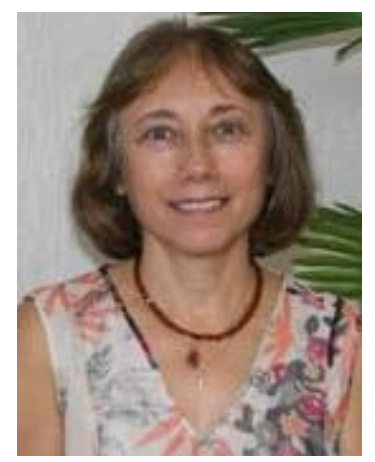

\title{
Temas de impacto
}

No presente volume, o leitor perceberá que há seis artigos originais e um artigo de revisão, os quais abordam temas presentes nas discussões entre os meios acadêmicos e em outros meios de comunicação, como as substâncias psicoativas, a violência no trabalho em psiquiatria e o suicídio.

Em dois artigos, discute-se o tratamento das dependências de substâncias psicoativas, com a descrição das instituições (abertas e fechadas) disponíveis para isso, bem como a adesão dos trabalhadores aos modelos teóricos que definem esse tratamento, que, em última instância, deveriam estar afinados com os fundamentos defendidos pelas mesmas.

Esse resultado vem de encontro à peculiaridade no contexto da assistência à saúde no Brasil, em que se verifica o fenômeno da convivência antagônica de perspectivas, testemunho das contradições do modelo brasileiro, pois, embora preconize a política de redução de danos, com os Centros de Atenção Psicossocial para atendimento dos problemas relativos ao uso de substâncias psicoativas como modelo, esse coexiste com as comunidades terapêuticas (religiosas ou não) ${ }^{(1)}$, como órgãos prestadores de assistência, as quais não se enquadram nas diretrizes institucionais do Sistema Único de Saúde (SUS $)^{(2)}$, o que constitui ponto relevante a ser considerado no debate sobre tais instituições, o cuidado que oferecem e o papel que ocupam nas sociedades.

Além disso, é preciso reconhecer que o trabalho profissional, na proposta do Modelo Psicossocial (originado no movimento da reforma psiquiátrica), demanda flexibilidade nos papéis profissionais, solicitando certa polivalência dos trabalhadores. Entretanto, há de se considerar que uma coisa é o trabalho prescrito pelo projeto de saúde mental e outra é o trabalho real, efetivamente realizado pelos trabalhadores, ponto que, no artigo em questão, é exposto com propriedade.

Alguns profissionais legalmente possuem responsabilidade direta sobre os usuários, sobre a gestão de procedimentos e/ou a gestão do próprio serviço, o que pode conduzir a comportamentos de controle excessivo e de centralização decisória que precisam ser trabalhados, no contexto dos serviços, por meio de relações francas e abertas ao diálogo. A maior parcela de responsabilidade não deve inviabilizar o compartilhamento de saberes, a confiança na competência do outro e o processo de tomada de decisões mais pactuado. $O$ equilíbrio entre posições não é tarefa fácil e exige habilidades que, com tempo, prática, empenho e conhecimento, podem ser adquiridas.

Os transtornos mentais e comportamentais por uso de substâncias psicoativas representam, nas internações de hospital psiquiátrico, um peso considerável. Em estudo apresentado neste volume, evidencia-se esse fato, assim como a importância da atuação profissional em que seja privilegiada a perspectiva de saúde mental ampla que incorpore, efetivamente, os transtornos devidos às adições. A título de reflexão, cabe lembrar que as condições neuropsiquiátricas que mais contribuem para a incapacidade ajustada aos anos de vida são os transtornos afetivos unipolar e bipolar, os transtornos por uso de álcool e outras substâncias psicoativas, a esquizofrenia e a demência ${ }^{(3)}$, portanto, os resultados desse trabalho corroboram tal dado.

Destaca-se, ainda, que, em um ranking global de fatores de risco na carga total de doenças (na faixa entre os 15 e 49), o uso de álcool aparece em primeiro lugar, fato importante enquanto investimento na prevenção da mortalidade por acidentes e condições neuropsiquiátricas, decorrentes do consumo dessa substância, pois, 
entre os homens, o álcool e o tabaco causaram carga relativamente grande de doenças, quando comparados a outros fatores de risco(4).

Assim, é cada vez mais frequente observar que, no caso das adições, o usuário não apresenta um único problema de saúde, a comorbidade é fato recorrente, e não só em transtornos mentais e comportamentais, mas em outras doenças orgânicas e infecciosas, sendo responsabilidade do profissional prestador de cuidados atentar-se a essa realidade, que não é tão nova, mas tem se imposto com mais veemência nos últimos anos.

O crack surgiu no final da década de 1980 no Brasil e, hoje, é fonte de inquietação nacional. Em virtude de seu caráter enigmático, complexo e multidimensional, mobiliza a sociedade, os estudiosos, a mídia e, inclusive, os religiosos ${ }^{(5)}$.

Neste volume, foram incluídos estudos nos quais se discorre sobre consequências do uso das substâncias psicoativas para a pessoa usuária de cocaína-crack e, nesse caso, as possíveis alterações de comportamento, como o déficit de atenção e hiperatividade, presentes na comparação entre usuários e não usuários. Também em revisão sistemática, expõe-se o desafio que é para o usuário lidar com a compulsão pelo uso, os sintomas relatados no momento da fissura e as estratégias que utilizam para manejar o desconforto, com destaque dos autores para a necessidade de aprofundar os estudos na influência dos fatores individuais, interpessoais e sociais a respeito da fissura.

O processo de ajuda ao usuário não é fácil e demanda esforço e envolvimento de muitas instâncias, desde os serviços de saúde e assistência social, que promovem vínculos com os usuários, até os possíveis elementos que possam ser incluídos como parte da sua rede de apoio. Nesse caminho, é importante reforçar a habilidade do usuário para enfrentar a "fissura"(6), possibilitar o atendimento integral ao indivíduo e fortalecer a rede psicossocial, no intuito de auxiliar na recuperação ou estreitamento de laços com grupos da sociedade ${ }^{(7)}$.

O medo da volta ao uso é constante nos participantes, pois, frequentemente, há entre os indivíduos que fazem uso de drogas muitas incertezas, medos e questionamentos a respeito da sua capacidade para superar ou controlar o uso(8).

Nos últimos tempos, são recorrentes no país campanhas de conscientização e programas específicos do governo, como estratégias de "combate". Como decorrência disso, é mais que oportuno apresentar trabalhos que tragam contribuições para o conhecimento de aspectos relacionados ao uso dessa substância.

Outro tema pouco explorado nos estudos que se referem à saúde mental, abordado em artigo no presente volume, diz respeito à percepção de enfermeiros sobre a violência no ambiente de trabalho na área de psiquiatria, cujos resultados apontam, como focos de origem, membros da equipe de saúde, o próprio paciente, o familiar do mesmo e a própria instituição, que não disponibiliza os recursos materiais e humanos necessários para a realização do trabalho. Os autores alertam sobre as possíveis repercussões no desempenho laboral e na saúde dos trabalhadores de enfermagem.

O sofrimento no trabalho é definido a partir do fator desgaste, por meio do cansaço, do descontentamento com as relações profissionais e da divisão de tarefas. A rigidez hierárquica, os procedimentos burocráticos, a falta de participação nas atividades e a pouca perspectiva de crescimento profissional são fatores importantes geradores de sofrimento. Além disso, em virtude de diferenças entre a tarefa prescrita e a atividade realmente desempenhada, o sujeito coloca-se em situação de esforço permanente para dar conta da sua realidade de trabalho(9).

Infelizmente, esse cenário parece ser bastante comum entre os trabalhadores de enfermagem, o que é grave, pois tal situação culmina com repercussões para o desempenho na assistência, interfere na satisfação profissional e, finalmente, na saúde desse trabalhador.

No entanto, no enfrentamento das situações geradoras de sofrimento, o apoio institucional e a colaboração de colegas podem contribuir para a normalidade, uma vez que esses suportes mudam a forma de percepção e, ao invés de sobrecargas, essas situações passam a ser encaradas como desafios, especificamente na enfermagem, como oportunidades de exercício da criatividade, da solidariedade e da parceria, o que, nesse caso, transforma o sofrimento em prazer ${ }^{(9)}$.

Portanto, a forma de gerenciar o espaço de trabalho e as relações estabelecidas entre os membros no interior da equipe e entre as diversas equipes profissionais, que, no caso específico, compõem o serviço de saúde, estabelece a diferença entre vivenciar o sofrimento ou o prazer no trabalho.

O suicídio é um tema relegado em detrimento de outros, a despeito de sua importância os pesquisadores de saúde parecem pouco inclinados à pesquisa, e os trabalhadores, bastante temerosos em manejar situações 
que possam envolver essa condição, é o que se sugere no estudo aqui exposto, em que os autores buscam descrever as ações realizadas por enfermeiros da atenção básica na prevenção do suicídio.

O suicídio tem sido abordado de acordo com duas perspectivas aparentemente opostas, de um lado, como resultante de fatores originários do contexto social e cultural e, de outro, focalizado como consequência única proveniente de características e experiências individuais, as quais levam o sujeito a atentar contra a própria vida. A perspectiva da saúde pública aproxima-se da posição dirigida à prevenção do suicídio, contudo, para isso há necessidade de integrar ambos os pontos de vista a fim de desenvolver estratégias que beneficiem a maioria das vidas de maneira efetiva e mensurável(10).

Os programas de prevenção de suicídio com uso de estratégias de saúde pública são iniciativa recente ${ }^{(11)}$, a mais comum é a focalização de ações em grupos de alto risco (portadores de depressão grave e outras doenças mentais) e promoção de estratégias orientadas para essa população. Essa estratégia, por si só, não tem sido a mais efetiva, pelo seu caráter restritivo a enfermidades mentais enquanto fatores de risco, no planejamento de ações preventivas, pois essas doenças estão sujeitas a altas taxas de falsos positivos ${ }^{(12)}$, o que diminui os benefícios esperados com a implementação do programa.

Estratégia bastante utilizada para a redução dos suicídios tem sido a modificação ambiental, assim denominada por ter como orientação a restrição dos meios existentes no ambiente utilizados em tentativas de suicídio, considerando que a probabilidade de tentativa de suicídio decresce quando o indivíduo não possui disponíveis os meios que utilizaria para a autoagressão. No entanto, isso não significa que ele não utilize métodos diferentes, acessíveis e, talvez, menos letais. O que já é um benefício, pois, da perspectiva da saúde pública e da prevenção de danos, a escolha de métodos cuja letalidade é menor pode reverter em vantagem, caso a tentativa não termine em morte ${ }^{(10)}$.

Nos resultados do artigo apresentado, mostram-se profissionais enfermeiros sensibilizados para compreender a relevância do problema suicídio, todavia, sentem-se incapazes de lidar com ele, seja por não sentirem afinidade com o problema ou por avaliarem que não dispõem de habilidades específicas que, no caso de outras doenças ou problemas de saúde, teriam disponibilidade para adquirir por meio de treinamentos.

Essa questão torna-se mais complicada, pois o comportamento suicida, em geral, é resultado de interações complexas de fatores socioambientais, comportamentais e psiquiátricos ${ }^{(11)}$. A capacitação das equipes de saúde para prevenir essa condição, que atinge dramaticamente os mais diversos grupos das comunidades, requer amplo enfoque de saúde, especialmente de saúde mental, voltado atentamente às diversas pressões da sociedade, possíveis desencadeantes de sofrimento, tanto quanto às vulnerabilidades individuais que acometem os membros desses grupos.

Também, urge-se discutir o tema na formação dos profissionais prestadores de cuidados à população e, certamente, no contexto dos serviços de saúde, em encontros de apoio e educação continuada (que são cada vez mais necessários) e não somente em ocasiões pontuais, quando surgem episódios de suicídio ou tentativa que causam comoção nos espaços nos quais ocorrem, sejam eles de ensino ou trabalho. Atentar contra a própria vida, ou ter sucesso em evento cujo objetivo era esse, frequentemente gera naqueles que convivem ou conviveram com o perpetrador da autoagressão sentimentos de perplexidade, raiva, culpa, inconformismo e muitos outros, nenhum deles agradável, e justamente esse conjunto de emoções deve emergir e ser trabalhado entre as pessoas que vivenciam experiências dessa natureza, inclusive em locais onde se pretende implementar programas de prevenção, o conteúdo relativo às emoções suscitadas por tentativas de suicídio e suicídio deve ter papel de relevância.

\section{Referências}

1. Alves VS. Modelos de atenção à saúde de usuários de álcool e outras drogas: discursos políticos, saberes e práticas. Cad Saúde Pública. 2009; 25(11):2309-19. Disponível em: http://www.scielo.br/pdf/csp/v25n11/02.pdf

2. Moreira RM, Fernandes RBFM, Ribeiro MJ, Franco LT Neto. Uma revisão da produção científica brasileira sobre o crack - contribuições para a agenda política. Ciênc Saúde Coletiva. [Internet]. 2015 [cited Jan 7, 2017];20:1047-62. Disponivel em:<http://www.scielo.br/scielo.php?script=sci_arttext\&pid=\$1413-81232015000401047\&lng=en\&nrm=i so>. ISSN 1413-8123. http://dx.doi.org/10.1590/1413-81232015204.03202014.

3. Prince M, Patel V, Saxena S, Maj M, Maselko J, Phillips M, et al. No health without mental health. Lancet. 2007;370:859-77. 
4. Shield KD, Rehm J. Global risk factor rankings: the importance of age-based health loss inequities caused by alcohol and other risk factors. BMC Res Notes. 2015 Jun 9;8:231. doi: 10.1186/s13104.

5. Pulcheiro G, Stolf AR, Petternon M, Fensterseifer DP, Kessler F. Crack: da pedra ao tratamento. Rev AMRIGS. 2010;54(3):337-43.

6. Zeni TC, Araújo RB. Relação entre o craving por tabaco e o craving por crack em pacientes internados para desintoxicação. J Bras Psiquiatria. 2011;60(1):28-33.

7. Costa PHA, Motan DCB, Paiva FS de, Ronzani T. Destando a trama das redes assistenciais sobre drogas. Ciênc Saúde Coletiva. 2015;20(2):395-406.

8 Almeida CS, Luis MAV. Sociodemographic characteristics and pattern of use of crck and other drugs in a CAPS AD. Rev Enferm UFPE On Line. 2017;11:1716-23.

9. Mendes AMM, Tamoyo A. Valores organizacionais e prazer-sofrimento no trabalho. Psico-USF. 2001;6:39-46.

10. Yip PSF, Caine E, Yousuf S, Chang S-S, Kevin C-CW, ChenY-Y. Means restriction for suicide prevention. Lancet. [Internet]. 2012 [cited Feb 13, 2017];379. Available from: www.thelancet.com

11. Knox KL, Conwell Y, Caine EDIF. Suicide a public health problem, what are doing to prevent it ? Am J Public Health. 2004;94:37-45.

12. Oquendo MA, Currier D, Mannn JJ .Prospective studies of suicidal behavior in major depressive and bipolar disorders: What is the evidence for predictive risk factors? Acta Psychiatr Scand. 2006;114:151-8.

Margarita Antonia Villar Luis

Editora Chefe da SMAD, Revista Eletrônica Saúde Mental Álcool e Drogas, Professor Titular da Escola de Enfermagem de Ribeirão Preto, Universidade de São Paulo, Centro Colaborador da OPAS/OMS para o Desenvolvimento da Pesquisa em Enfermagem, Brasil. E-mail: margarit@eerp.usp.br 